\title{
Water Seepage Source at the Extension of Tourah Clay Quarry, Southeastern Cairo Based on Geological and Geoelectrical Resistivity Measurements
}

\author{
Ahmed Abd El-Gawad \\ Department of Geophysics, Faculty of Science, Ain Shams University, Cairo, Egypt \\ Email address: \\ ahmedm@sci.asu.edu.eg \\ To cite this article: \\ Ahmed Abd El-Gawad. Water Seepage Source at the Extension of Tourah Clay Quarry, Southeastern Cairo Based on Geological and \\ Geoelectrical Resistivity Measurements. Earth Sciences. Vol. 9, No. 3, 2020, pp. 108-116. doi: 10.11648/j.earth.20200903.13
}

Received: April 19, 2020; Accepted: May 7, 2020; Published: May 27, 2020

\begin{abstract}
The cement industry depends essentially on the clay as one of the main raw materials for the industry. The Tourah clay quarry is one of the oldest and largest quarries of clays in Egypt, which is located to the southeastern of Cairo. The biggest problems that affect the clay quarries and may cause them to be closed forever is that, the water reaches them and leads to the difficulty of extracting raw materials from the quarries and ultimately leads to their closure. During the mining operations and extraction of raw materials from the extension of Tourah clay quarry, a water leak was observed that reached the bottom of the quarry, and the water began to increase and led to the difficulty of entering and exiting the equipments from the quarry. A detailed geological field study and geoelectrical resistivity survey were conducted in and around the extension of Tourah clay quarry to find out the source and cause of the water leak, which was increasing rapidly on the bottom of quarry. A geoelectrical resistivity survey was performed in the form of thirteen vertical electrical soundings and two horizontal profiling were made using the Wenner configuration in order to understand and solve the formentioned problem. The interpretation of the geoelectrical data shows three main units; surface layer from dry sand, gravel and rock fragments followed by a second layer of loose sand and is partially saturated with water and finally a clay layer which is extracted as a raw material in cement industry. Accordingly, based on the field geological observations in addition to the geoelectrical resistivity interpretations, we can conclude that, the possible water source in the bottom of clay quarry is due to the second loose partially saturated sand unit and the direction of water invasion in this particular area comes from the northeastern direction. To save the extension of Tourah clay quarry from closure it is recommended to extract the water from the sand unit before it reached the quarry bottom either by water head compensation or dewatering of the well field area.
\end{abstract}

Keywords: Water Seepage, Clay Quarry, Geoelectrical Resistivity Measurements, Cairo, Egypt

\section{Introduction}

Tourah clay quarry is one of the largest clay quarries in Egypt and the oldest clay quarry for cement plant in Africa. The depth of the quarry is $70 \mathrm{~m}$., it is below the sea level by $40 \mathrm{~m}$. The total quarry area is $1.5 \mathrm{Km}^{2}$. Currently the quarry is surrounding by many civil military and cultivated areas. An important highway and railway run adjacent to the west and east sides of the quarry. The quarry is very close to the cement plant. the extension of Tourah clay quarry is located to the northwestern part to the original clay quarry and southeastern to Cairo. It is located between latitudes $29^{\circ} 54^{\prime} 54^{\prime \prime}$ and $29^{\circ} 55^{\prime} 11^{\prime \prime}$ north and longitudes $31^{\circ} 17^{\prime} 42^{\prime \prime}$ and $31^{\circ} 18^{\prime} 08^{\prime \prime}$ east. The location map of the study area is shown in Figure 1.

The Tourah clay quarry lies $\sim 20 \mathrm{Km}$. to the southeastern part of Cairo, on Maadi-Helwan road. The Middle Eocene limestone plateau bordering the Nile valley is dissected by numerous wadies. Tourah quarry deposits are mainly clays and silty clays of Pliocene age. These deposits attain more than $120 \mathrm{~m}$. in thickness. The location map of Tourah clay quarry and its northwestern extension is shown in Figure 2. 


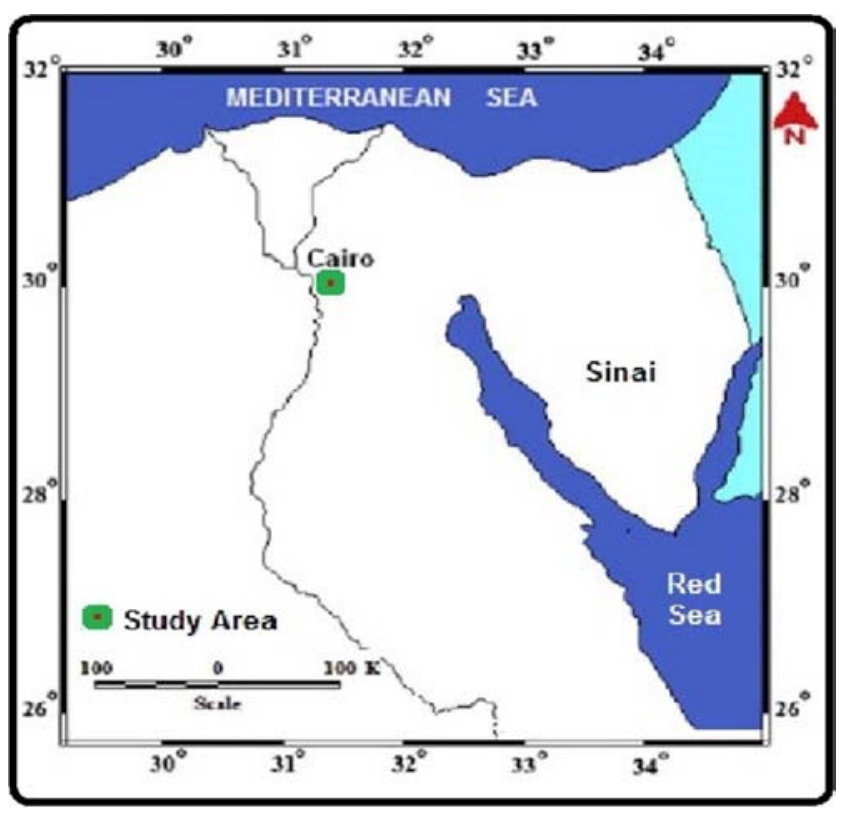

Figure 1. Location map of the study area.

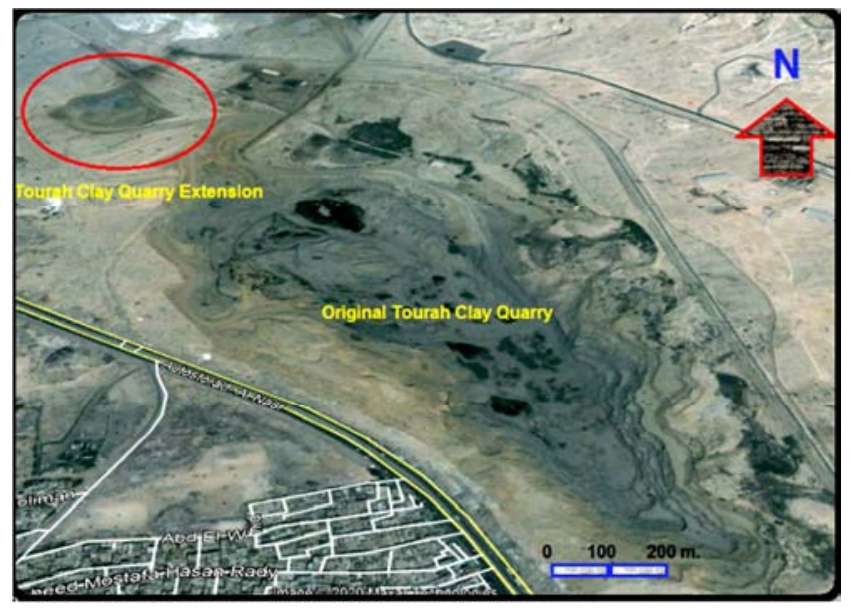

Figure 2. Location map of Tourah clay quarry and its northwestern extension (From Google Earth).

\section{Aim of the Present Work}

During the mining operations and extraction of raw materials from the extension of Tourah clay quarry, a water leak was observed that reached the bottom of the quarry, and the water began to increase and led to the difficulty of entering and exiting the equipments from the quarry (Figure 3 ). The main aim of the present work is to find out the source of the water leak which was increasing rapidly on the bottom of the extension of Tourah clay quarry in addition to recommend solutions for the formentioned case.

\section{Geological and Geoelectrical Survey}

The geologic setting of the area under investigation were studied by several workers; e.g. $[4,15,13,14,16,10,11]$ and [1]. The area under investigation is characterized by arid to semi-arid conditions, the study area has a group of valleys where their waters flow into the Nile River (the far west), their direction is from north-east and descends to the southwest and this is almost the trend of most cracks and joints in the area, so these valleys may have a structurally-controlled origin.

A precise field geological work in and around the extension of Tourah clay quarry is studied in addition to execution of thirteen vertical electrical soundings and two horizontal profiles in an integration to find out the source of water which covers the bottom of the extension of Tourah clay quarry. A Terrameter SAS 300, manufactured by ABEMSweden, has been used in performing the geoelectrical resistivity measurements. The vertical electrical resistivity soundings using Schlumberger array is started from $\mathrm{AB} / 2=1$ $\mathrm{m}$ to $\mathrm{AB} / 2=100 \mathrm{~m}$. and the lengths of the two horizontal profiles are $74 \mathrm{~m}$. and $100 \mathrm{~m}$. The locations of the measured geoelectrical resistivity measurements are shown in Figure 4.
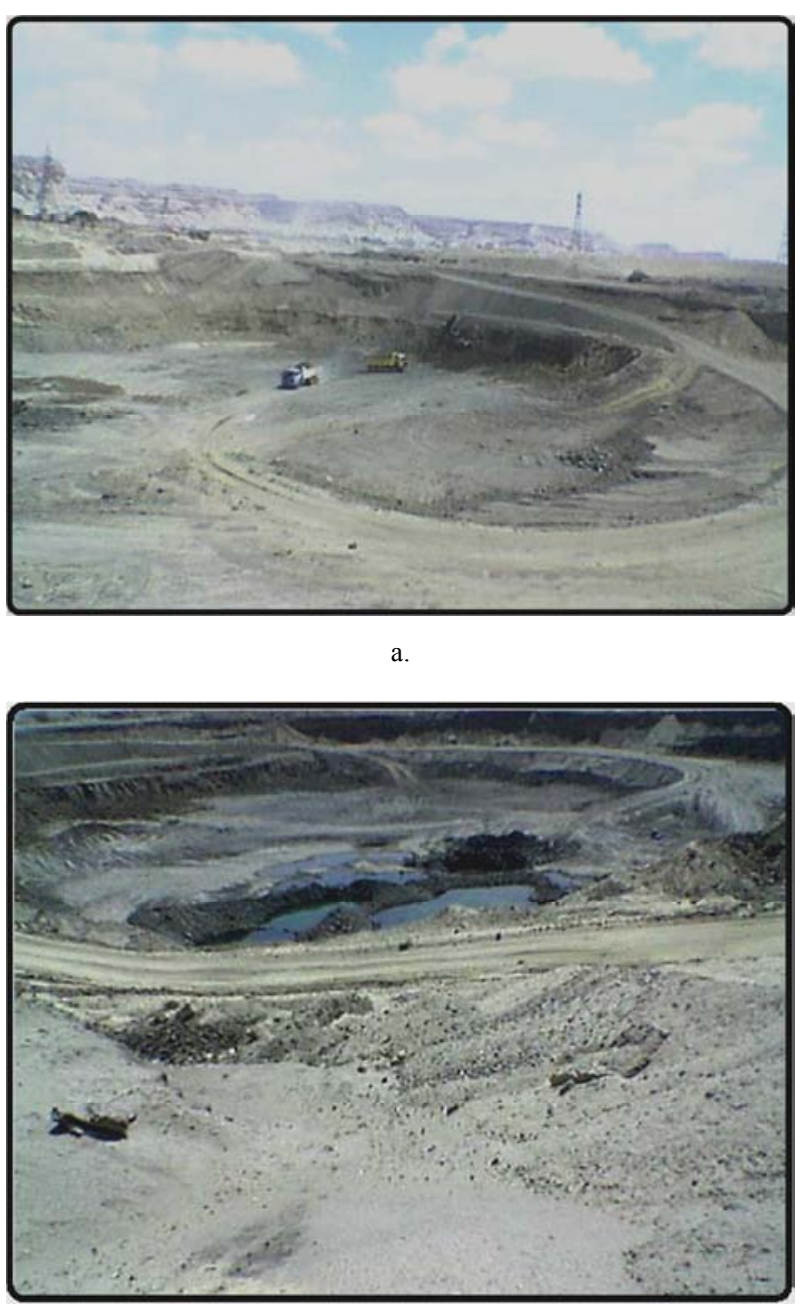

b.

Figure 3. a). Tourah clay quarry extension before water invasion; b). Tourah clay quarry extension after water invasion. 


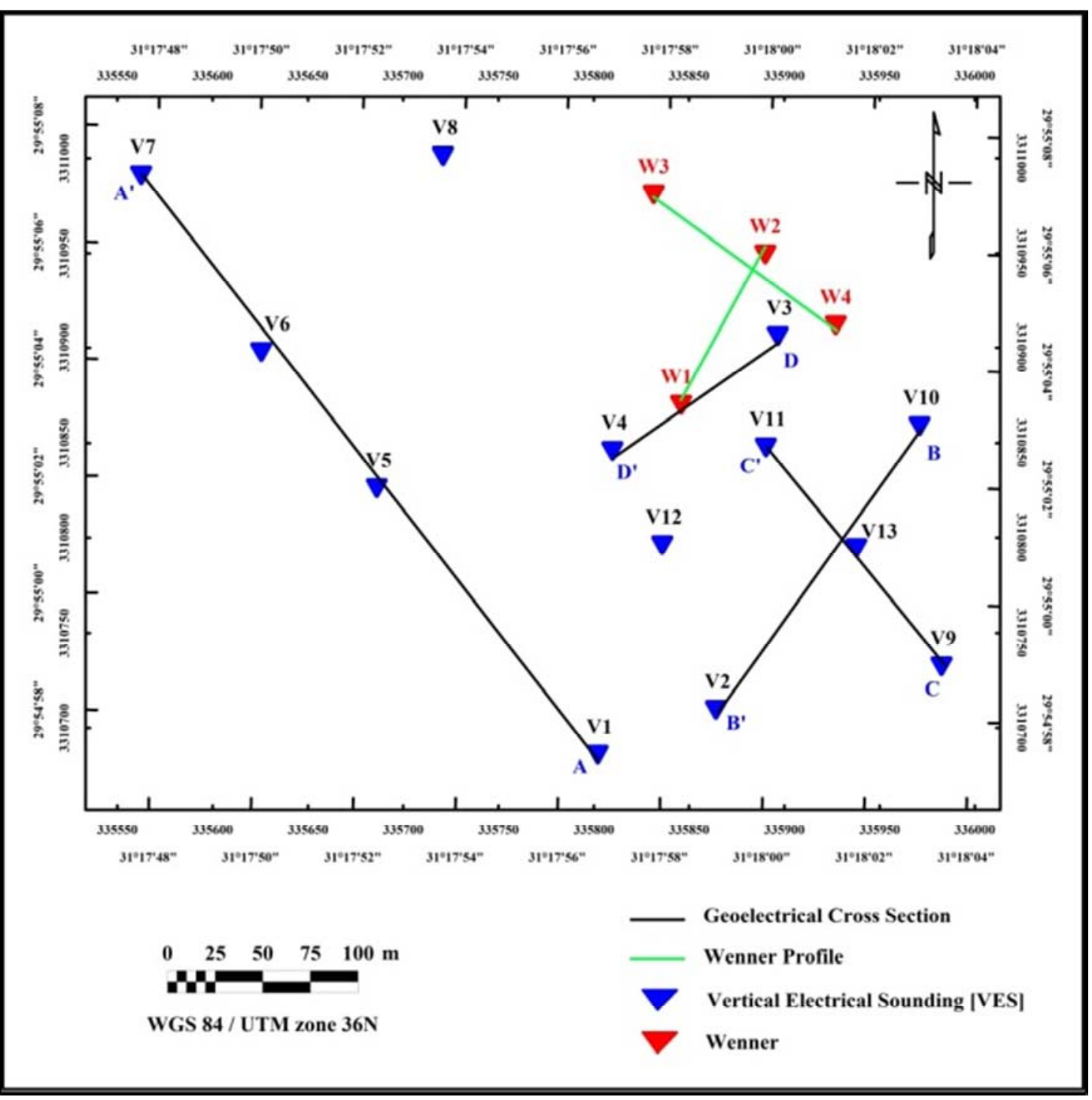

a.

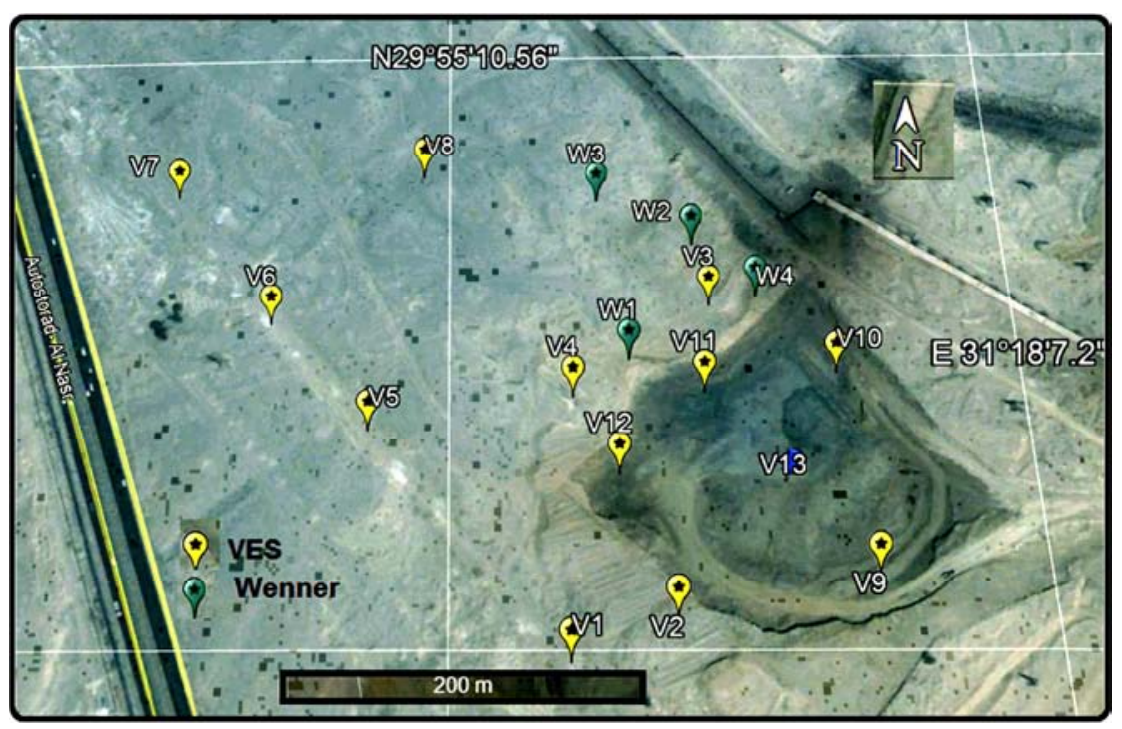

b.

Figure 4. a). Vertical electrical sounding and horizontal profiling location map; b). Vertical electrical sounding and horizontal profiling location map (From Google Earth). 


\section{Geoelectrical Interpretation}

The interpretation of the electrical resistivity sounding data aims firstly to determine quantitatively the true resistivities and thicknesses of the successive strata below the different stations utilizing the measured field curves. It is achieved purely on theoretical considerations and is popularly known as quantitative interpretation. Secondly, the geological interpretation translates the quantitative values into a realistic picture within the known geological framework. The interpretation of the electrical resistivity data is dealt with by several authors as $[17,5,6,7,8]$ and others.

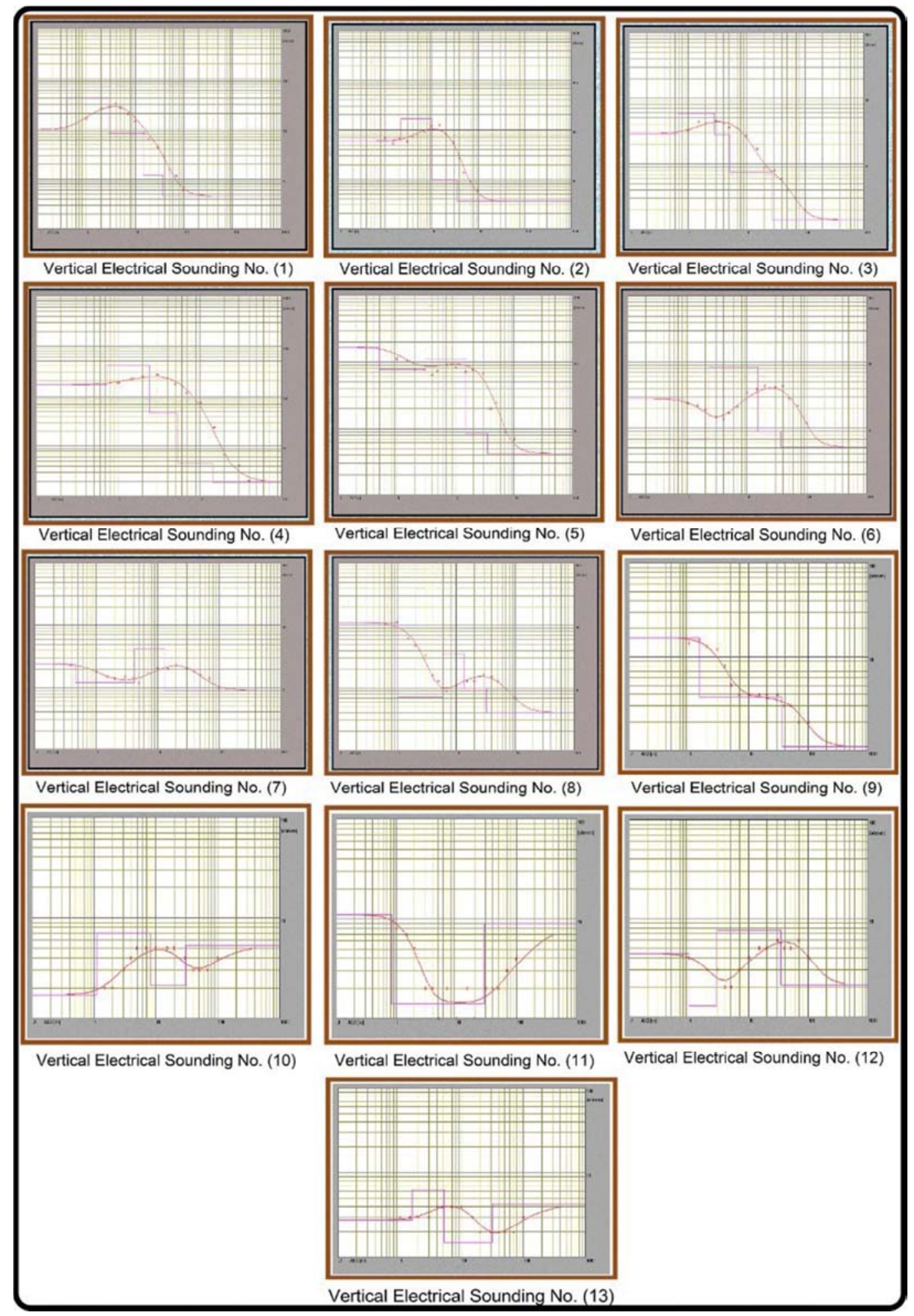

Figure 5. Interpretation of the vertical electrical sounding curves of the study area. 
Table 1. Vertical electrical sounding interpretation of the study area.

\begin{tabular}{llllllllll}
\hline VES No. & $\mathbf{\rho 1}$ & $\mathbf{\rho 2}$ & $\mathbf{\rho 3}$ & $\mathbf{\rho 4}$ & $\mathbf{\rho 5}$ & $\mathbf{h 1}$ & $\mathbf{h 2}$ & $\mathbf{h 3}$ & $\mathbf{h}$ 4 \\
\hline 1 & 97.0 & 420 & 82.0 & 12.0 & 4.6 & 0.39 & 2.5 & 12.3 & 22.0 \\
2 & 60.0 & 170 & 9.5 & 3.5 & - & 2.2 & 7.7 & 26.0 & - \\
3 & 29.0 & 59.0 & 28.0 & 7.7 & 1.4 & 0.67 & 2.2 & 2.3 & 22.0 \\
4 & 170 & 410 & 47.0 & 4.5 & 1.9 & 0.73 & 1.7 & 2.9 & 9.0 \\
5 & 170 & 77.0 & 110 & 8.5 & 4.2 & 0.5 & 2.5 & 12.0 & 20.0 \\
6 & 28.0 & 6.9 & 83.0 & 9.0 & 5.1 & 0.88 & 1.4 & 13.0 & 22.0 \\
7 & 24.0 & 12.0 & 42.0 & 9.1 & 9.1 & 0.46 & 3.7 & 8.9 & 22.0 \\
8 & 110 & 7.3 & 35.0 & 10.0 & 4.0 & 1.0 & 4.8 & 8.0 & 19.0 \\
9 & 16.0 & 3.7 & 1.1 & - & - & 1.5 & 35.0 & - & - \\
10 & 1.7 & 7.0 & 2.1 & 5.3 & - & 1.1 & 7.0 & 23.0 & - \\
11 & 11.0 & 1.4 & 9.0 & - & - & 0.84 & 28.0 & - & - \\
12 & 4.4 & 1.3 & 7.6 & 2.1 & - & 1.0 & 1.9 & 32.0 & - \\
13 & 2.8 & 6.3 & 1.5 & 4.3 & - & 1.6 & 3.6 & 26.0 & - \\
\hline
\end{tabular}

Electrical surveys are among the most difficult of all the geophysical methods to interpret quantitatively because of the complex theoretical basis of the technique [9]. Although nearly all VES interpretation is done now on desk-top computers by matching measured curves with model ones calculated by readily available, or easily constructed, programs based on specific principles, it will be instructive first to take a look at the most common of the older methods, namely that using master diagram [12].

In the present study, the geoelectrical resistivity data involve the interpretation of the thirteen vertical electrical sounding curves. Winsev 6.0 is simply a program provided by Geosoft Company (2004) for assisting in the interpretation of vertical electrical sounding curves. Winsev 6.0 is a forward and inverse modelling program for interpreting resistivity-sounding data in term of a layered earth (1-D) model. The interpretation of the vertical electrical sounding curves of the extension of Tourah clay quarry (Figure 5) show resistivity range from $1.1 \Omega \mathrm{m}$. to more than $420 \Omega \mathrm{m}$. The number of the interpreted geoelectrical units is three. The true resistivities and layer thicknesses are given in (Table 1).

The geoelectrical cross-sections can clearly reflect the actual geoelectrical picture of the subsurface conditions, that prevails in the area under consideration. The geoelectrical section when correlated with the available geologic information can access the geologic interpretation standing behind the conditions of the studied area. In the area under consideration, four geoelectrical cross-sections covering the extension of Tourah clay quarry and its surrounding areas are constructed; two of them are oriented NW-SE (AA $\backslash$ and $\mathrm{CC} \backslash$ ) and the others are directed NE-SW (BB $\backslash$ and $\mathrm{DD} \backslash)$.

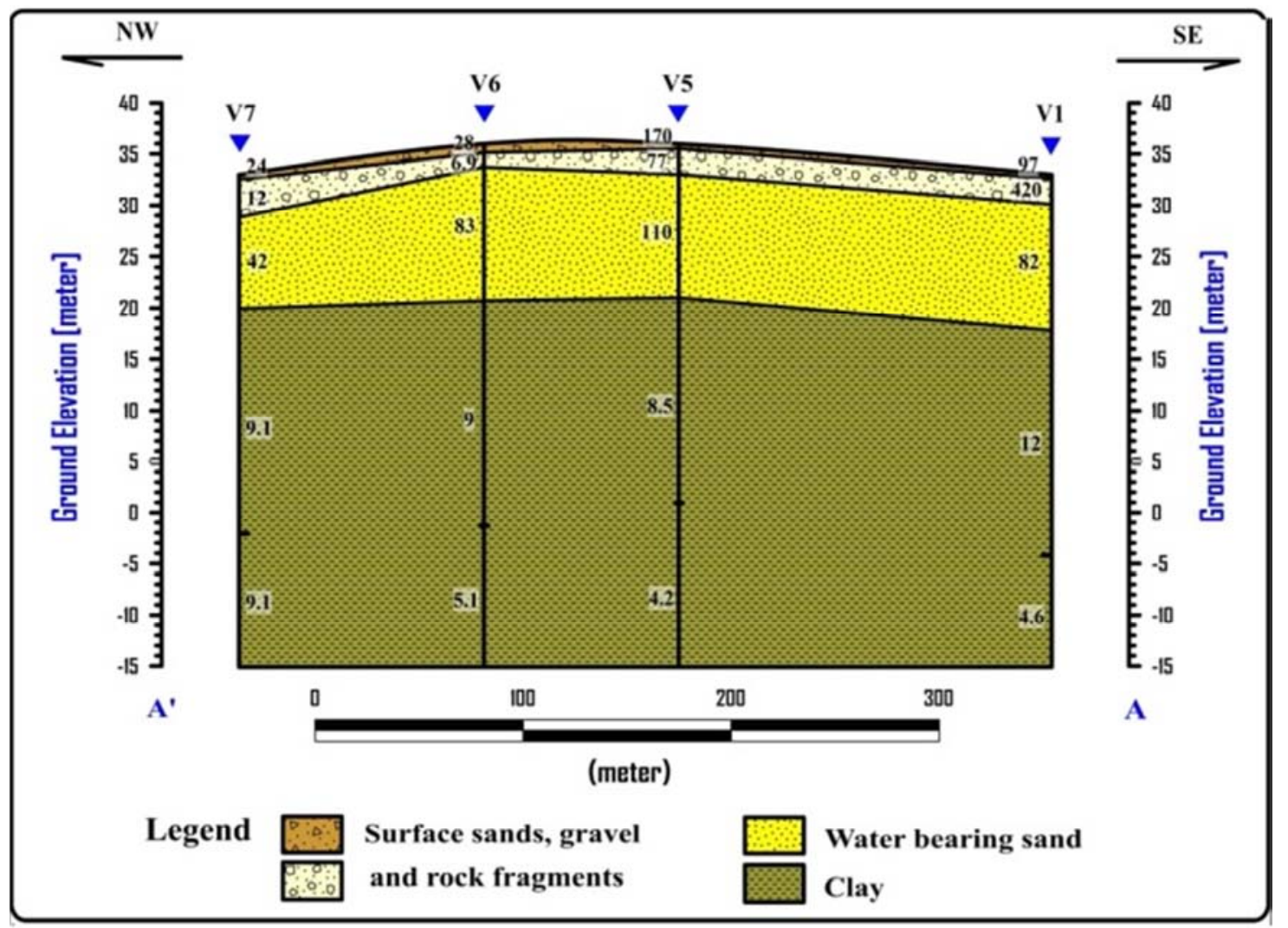

Figure 6. Geoelectrical cross-section AAl. 


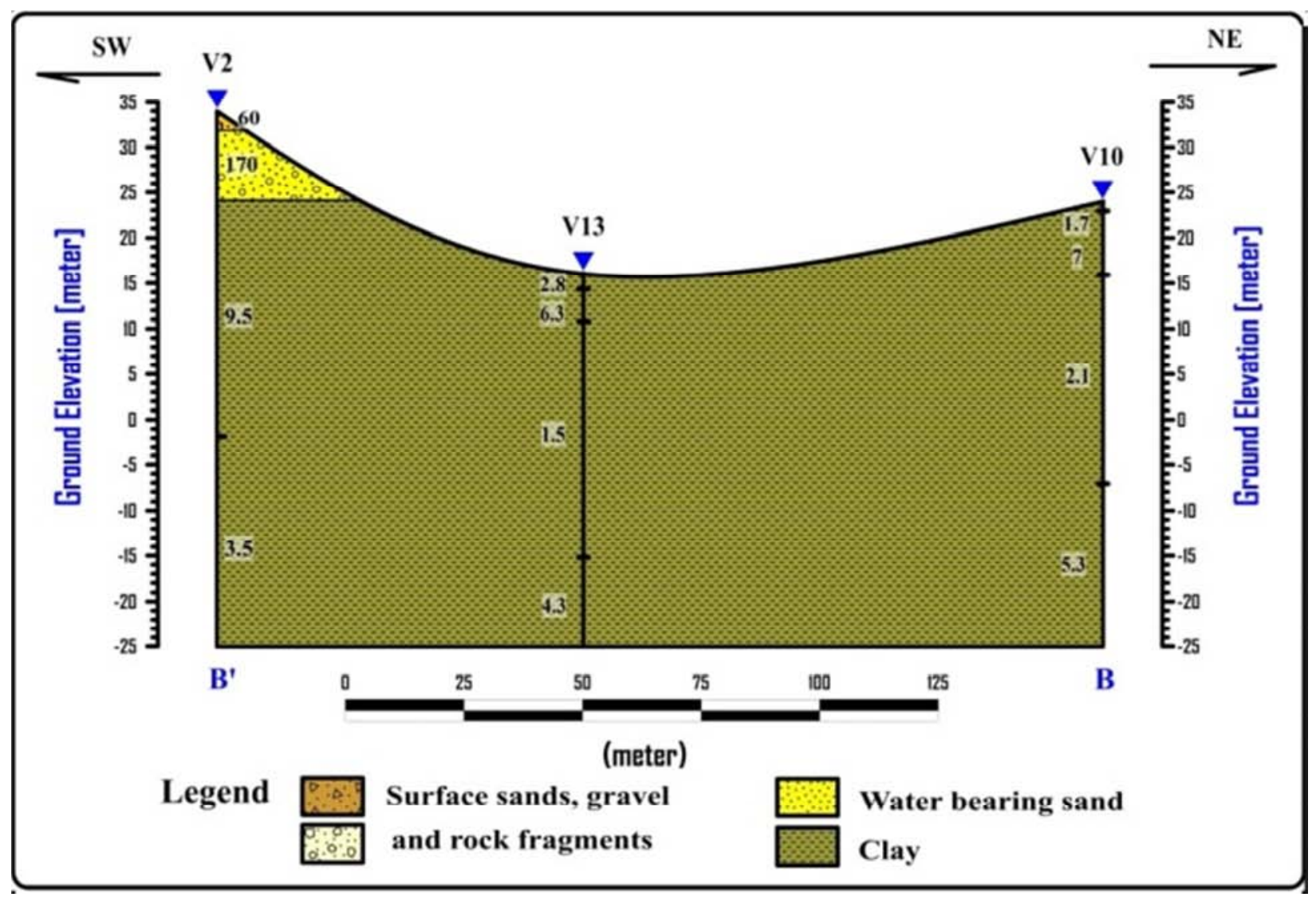

Figure 7. Geoelectrical cross-section $B B \mid$.

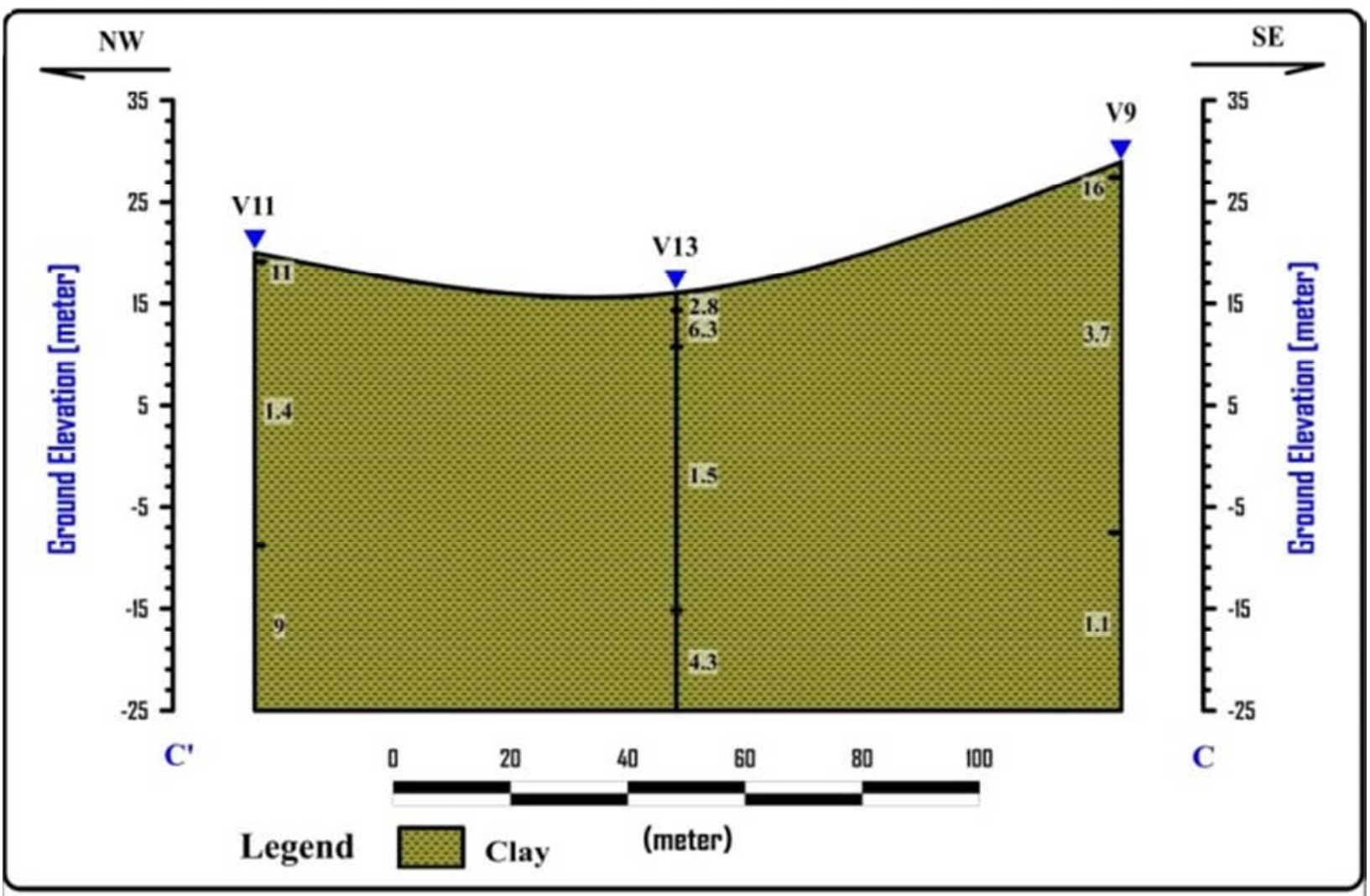

Figure 8. Geoelectrical cross-section CCl. 


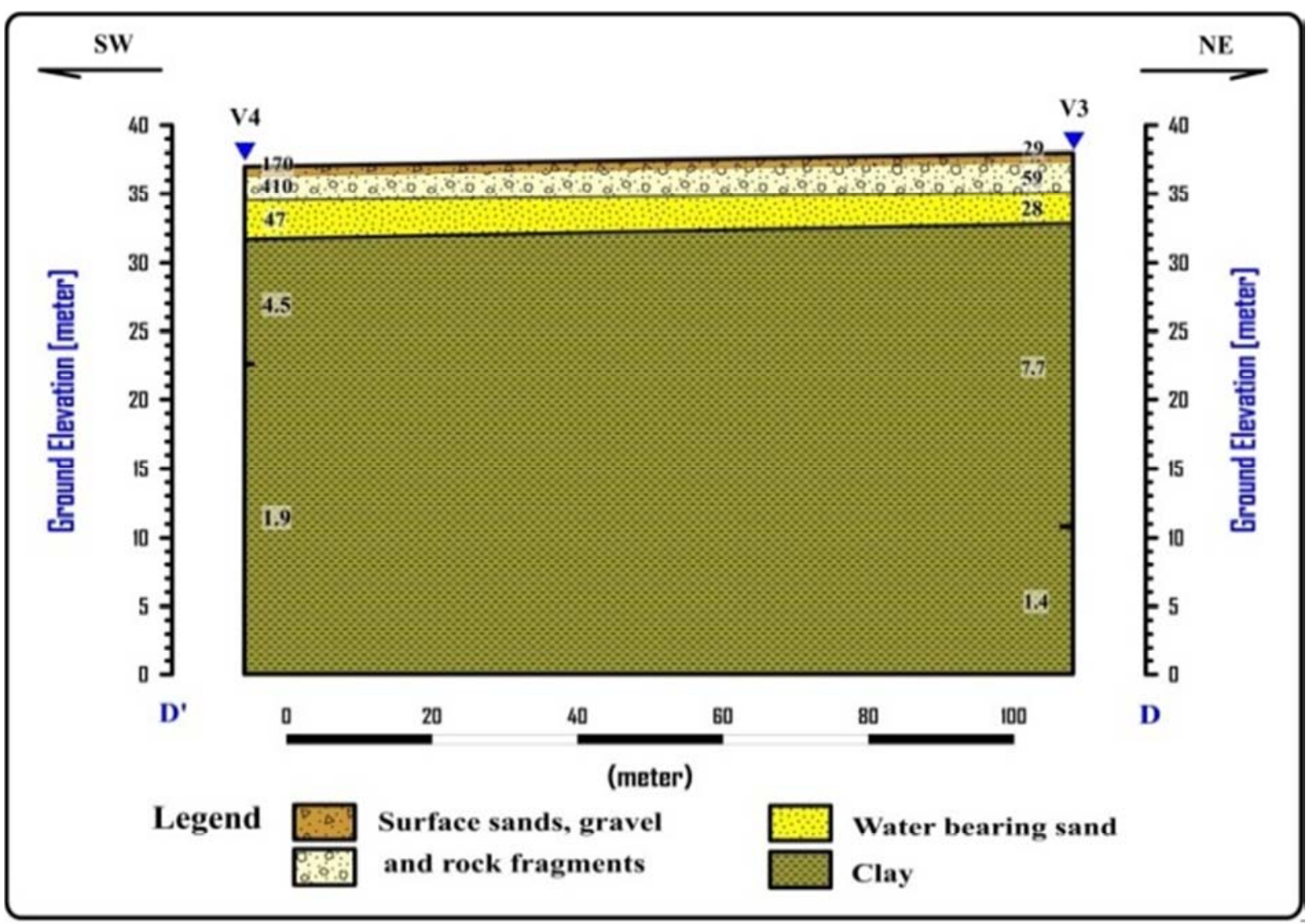

Figure 9. Geoelectrical cross-section $D D$.

From the previous vertical electrical sounding interpretation in addition to the geoelectrical cross-sections (Figures 6, 7, 8 and 9), it can be concluded that; The subsurface geological sequence in the area under investigation is considered essentially of three geoelectrical units; The first geoelectrical unit (first and second layers) is characterized by relatively low, moderate to high electric resistivity value ranged between $6.9 \Omega \mathrm{m}$ (VES No. 6), $29 \Omega$ $\mathrm{m}$ (VES No. 3), and $420 \Omega \mathrm{m}$. (VES No. 1). The thickness of this unit is ranged between $0.39 \mathrm{~m}$. (VES No. 1) and $4.8 \mathrm{~m}$. (VES No. 8), which corresponds to the surface sand, gravel and rock fragments unit. The second geoelectrical unit is characterized by relatively moderate electric resistivity value ranged between $28 \Omega \mathrm{m}$. (VES No. 3) and $110 \Omega \mathrm{m}$. (VES No. 5). The thickness of this unit is ranged between $2.3 \mathrm{~m}$. (VES No. 3) to about 13 m. (VES No. 6) which corresponds to the water bearing sand unit which responsible for clay quarry problem. The third geoelectrical unit is characterized by relatively low electric resistivity value ranged between 1.4 $\Omega$ m. (VES No. 11) and $9.5 \Omega$ m. (VES No. 2) which corresponds to the clay unit which is the main unit used as a raw material for cement industry.

Wenner Two-Dimensional Pseudo-electrical crosssections: Two pseudo-sections of the apparent resistivity reflect both lateral and vertical variations of resistivity values.

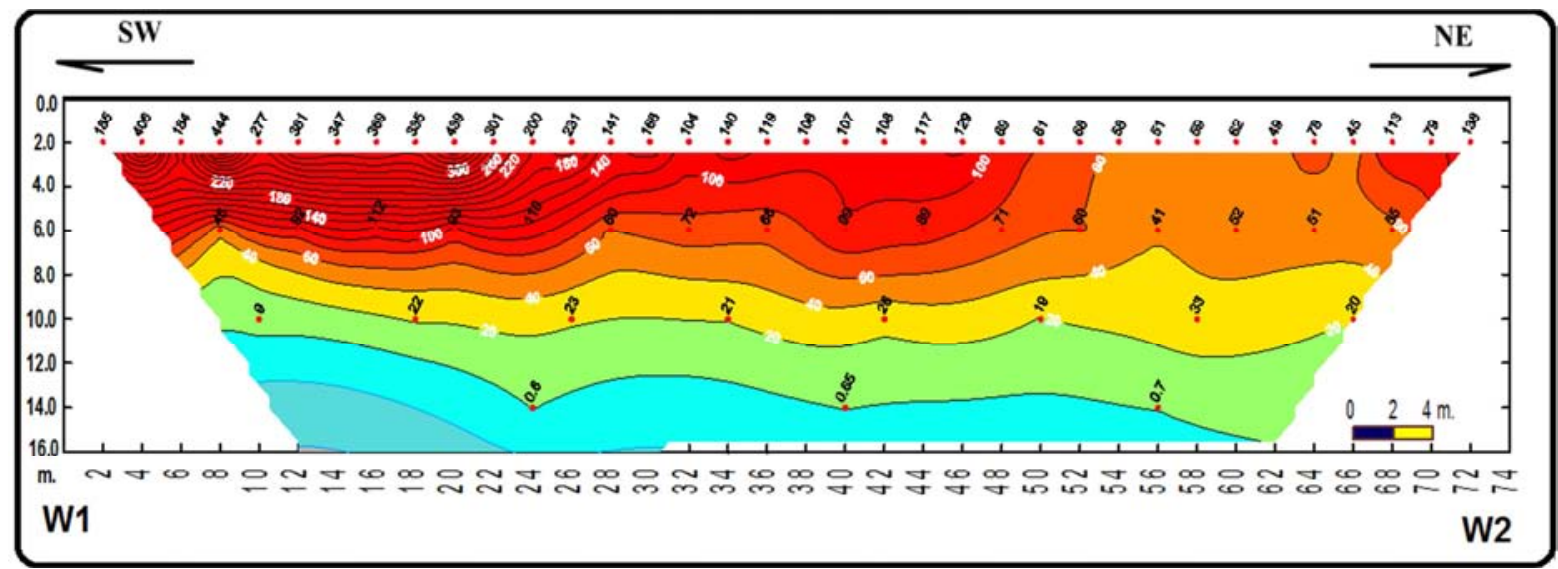

Figure 10. Horizontal electrical resistivity profile W1-W2. 
The first Wenner profile W1-W2 (Figure 10): This profile runs from southwestern to northeastern direction. The length of the profile is $74 \mathrm{~m}$. The geoelectrical units are arranged as follows: A resistive fairly compacted dry gravely sands of a maximum thickness of about $3 \mathrm{~m}$ at the southwestern part of the profile. The resistivity ranges between $120 \Omega$.m and $>300$ $\Omega . \mathrm{m}$. The second unit is friable sands. The thickness of this zone ranges between $\sim 2 \mathrm{~m}$ at the southwestern corner. It is exposed on the surface and reaches $\sim 7 \mathrm{~m}$ at the northeastern part of the profile. This layer is partially saturated with water. The resistivity increases within the layer from base to top where it ranges between $\sim 20 \Omega . \mathrm{m}$. and $>70 \Omega . \mathrm{m}$. respectively. The base of the succession is the sticky clay unit.

The second Wenner profile W3-W4 (Figure 11): This profile runs from northwestern to the southeastern direction. The length of the profile is $100 \mathrm{~m}$. The geoelectrical units are arranged as follows: A resistive fairly compacted dry gravely sand bed of a maximum thickness of about $2 \mathrm{~m}$ at its middle part. The resistivity ranges between $70 \Omega . \mathrm{m}$ and $>150 \Omega$.m. The second layer is friable sands. The thickness of this zone ranges between $\sim 0.2 \mathrm{~m}$ where the underlying clay layer is exposed at the northwestern part of the profile, and $5 \mathrm{~m}$ at the southeastern portion. This layer is partially saturated with water at its base. The base of this layer shows a highly irregular surface. The resistivity increases from base to top where it ranges between $\sim 20 \Omega . \mathrm{m}$. and $>50 \Omega . \mathrm{m}$. respectively. The base of the sedimentary succession is the sticky clay unit.

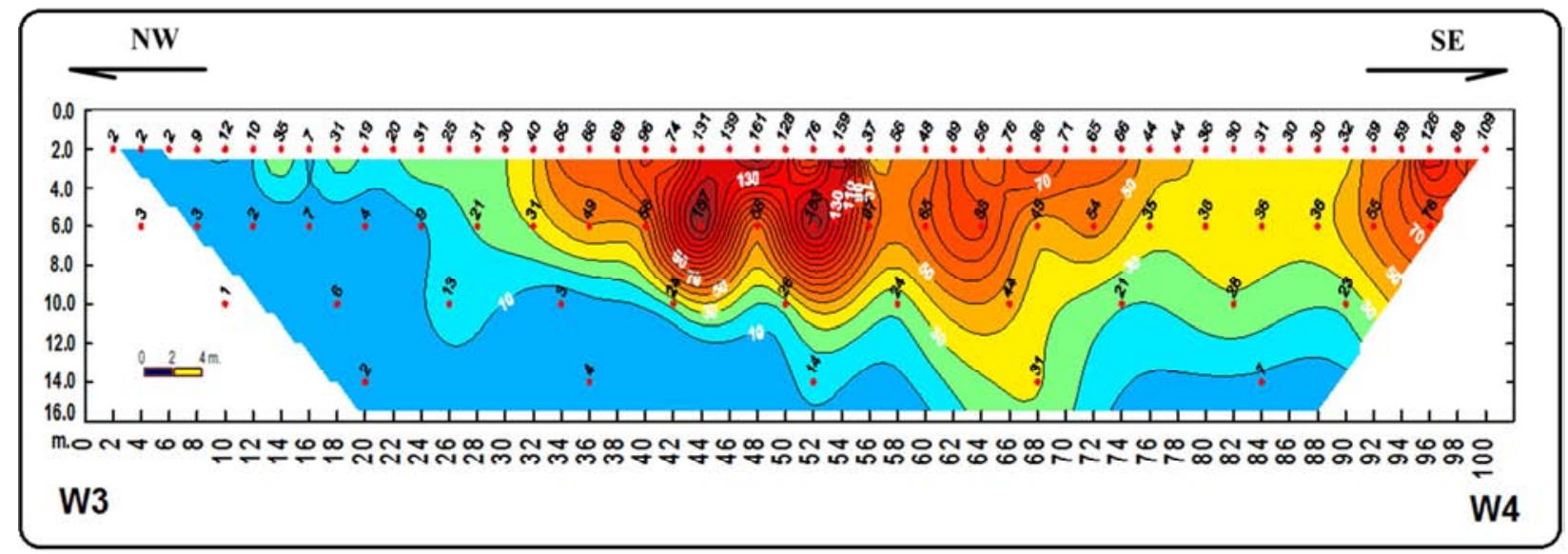

Figure 11. Horizontal electrical resistivity profile W3-W4.

The visual inspection of the two-dimensional pseudosections shows the following characteristics; The accumulated water is discharged from the friable sand layer in a topographically low zone directed NNE-SSW; The clay layer is exposed at the northwestern part of the area surrounding the quarry; which prevents the flow of water to the southern and southwestern direction; Generally, the apparent resistivity behavior is more or less the same along the two profiles; The apparent resistivity values of the friable sands (second layer) shows an increase from base to top and The thickness of the upper two layers increases in the middle part of the investigated area. The boundaries of the thick sedimentary zone above the clay layer coincides with the observed surfaces of sliding blocks in clays.

\section{Discussions and Conclusions}

The main goals of the geophysical investigation in the extension of Tourah clay quarry are defining lithology and possibly the structures of the subsurface layers, in this particular area and identifying the source of accumulated waters at the bottom of the quarry. To realize these ideas, geo-electrical survey has been conducted. The results of such survey, in general, are the resistivities and thicknesses of subsurface layers. Lithology and water saturation have been proposed also from the resistivity values. Resistivity measured on the upper bench indicates dry fairly compacted gravely sandstones for the uppermost layer, which confirm the exposed rock types on the quarry walls. This layer rests on friable sands showing a reduction of resistivity with depth. The base of the sedimentary succession is clay as indicated from the extremely low resistivity values.

As observed in the field, the groundwater is discharged from the friable gravely sand bed via the fractures bounding the slumped clay blocks in a topographically low area at the northern portion of Tourah clay quarry extension. The resistivity distribution in the vertical section of the 2D Wenner pseudo-sections and also the true thicknesses of the two uppermost layers above clay, exhibit a general inclination of the multi $\mathrm{V}$-shaped upper surface of clay layer towards the southern direction. These $\mathrm{V}$-shaped features are the channel-ways from which the groundwater is discharged to the quarry bottom. However, to understand the direction of groundwater flow in this particular area (Figure 12) has been constructed. Considering the above-mentioned facts and the true resistivity distribution of the clay layer in the quarry area; the following conclusions can be drawn:

The clays prevent water passage from the surrounding areas except the water comes from the northeastern direction. 
This can easily be concluded from the distribution of clays in the vertical section, where clay exposures exist on the rim of the quarry from southern, western, and northern sides;

The surface of the clay layer at the water discharge area, i. e. at the northeastern direction, exhibits generally inclined Vshaped features towards the quarry floor. The clay surface inclination leads to a water head (difference in water level elevations) towards the southwestern direction, i.e. to the quarry floor.

The possible direction of water invasion in this particular area comes from the northeastern direction as in (Figure 12).

\section{Recommendation}

For best exploitation of the clays in the northern extension part of Tourah quarry it is recommended to extract the water from the sand layer before it reached the quarry floor. As it is known, the water table is inclined towards the quarry floor; this creates a head, by which the water flows to the exposed surface of the saturated bed. However, the proposed possible solution to stop the water discharge is two-folds:

1) Water head compensation: this means a reduction of pressure at the northeastern boundary of the Tourah quarry, namely from the northeastern area by drilling a number $\sim 10$ wells, on two parallel lines perpendicular to the water flow direction. These wells will reach only the upper surface of clay layer. PVC-pipes are installed in the drilled wells. These pipes are perforated and surrounded by gravels, especially in the water saturated zone. This system will compensate greatly the head as the pipe upper-ends are kept open, where a zone of lower pressure is formed in this spot. This leads to an increase of water retention time in this area before it reaches the quarry;

2) Dewatering of the well field area: the accumulated waters in the well field area is pumped to the surface by installing a pump in one of the wells in the middle of the drilled holes.

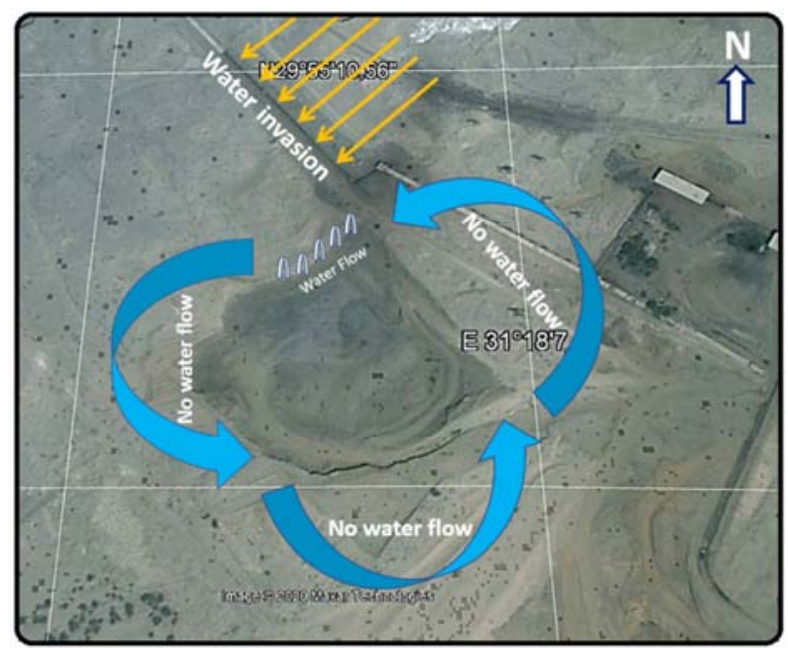

Figure 12. Water flow direction as interpreted from geological and geoelectrical work.

\section{References}

[1] A. M. S. Abd El-Gawad, "An integrative electrical resistivityshort seismic refraction study for delineating the Quaternary water occurrences in the south of Cairo, Egypt" M. Sc. Thesis, Fac. Sci., Ain Shams Univ., 1992, 303 p.

[2] A. M. S. Abd El-Gawad, and G. Hossam, "Application of geoelectrical measurements to detect the ground-water seepage in limestone quarry of Helwan, southeastern Cairo, Egypt" $4^{\text {th }}$ International Conference on the Geology of the Tethys, Cairo Univ., Nov., 2008, p. 141-148.

[3] A. M. S. Abd El-Gawad, A. S. Helaly, M. S. E. Abd El-Latif, "Application of geoelectrical measurements for detecting the ground-water seepage in clay quarry at Helwan, southeastern Cairo, Egypt” NRIAG, 2018 (7) p. 377-389.

[4] G. H. Awad, M. I Faris, and H. L. Abbass, "Contribution to the stratigraphy of the Mokattam area east of Cairo" Bull. Inst. Desert Egypte, 1953., v. 3, No. 2, p. 106-107.

[5] R. D. Barker, "Improving the quality of resistivity sounding data in landfill studies" In S. H. Ward (ed). "Geotechnical and environmental geophysics, v. 2. Environmental and ground water applications", 1990, p. 245-251.

[6] R. J. Bisdorf, "Schlumberger soundings at the Norman landfill, Norman, Oklahoma" U.S. Geological Survey 1996, Open-File Report 96-668.

[7] T. Dahlin, and B. Zhou, "A numerical comparison of 2D resistivity imaging with 10 electrodes arrays" Geophysical Prospecting, 2004, 52: p. 379-398.

[8] K. Ernstson, and R. Kirsch, "Geoelectrical methods, basic principles. -In Kirsch R (ed): Groundwater Geophysics: A Tool for Hydrology", Springer, 2006, p. 85-108.

[9] P. Kearey, and M. Brooks, "An introduction to geophysical exploration”, Blackwell Scientific Publication, London, 1991, $254 \mathrm{P}$.

[10] A. R. Moustafa, and S. Abdel Tawab, “ Morphostructures and non-tectonic structures of Gebel Mokattam", MERC, Ain Shams Univ. 1985, Sci. Res. Ser., v. 5, p. 65-78.

[11] A. R. Moustafa, M. A. Yehia and S. Abdel Tawab, "Structural setting of the area east of Cairo", Maadi, and Helwan: MERC, Ain Shams Univ., 1985, Sci. Res. Ser., v. 5, p. 40-64.

[12] D. S. Parasnis, "Principles of applied geophysics", Chapman \& Hall, 2-6 Boundary Row, London SE1 8HN, UK, 1997.

[13] R. Said, "The geology of Egypt" Elsevier Sci. Pub. Co., Amsterdam, 1962, $377 \mathrm{p}$.

[14] R. Said, "Explanatory notes to accompany the geological map of Egypt" Geol. Survey of Egypt, 1971, paper no. 56, 123 p.

[15] N. M. Shukri, "The geology of the desert east of Cairo" Bull. Inst. Desert Egypte, 1953, v. 3, no. 2, p. 89-105.

[16] A. Strougo, "Eocene stratigraphy of the eastern Greater Cairo (Gebel Mokattam-Helwan) area" MERC, Ain Shams University, 1985. Sci. Res. Ser., v. 5, p. 1-39.

[17] A. A. R Zohdy, "A new method for the automatic interpretation of Schlumberger and Wenner sounding curves" Geophysics, 1989, 54 (2): 245-253. 